
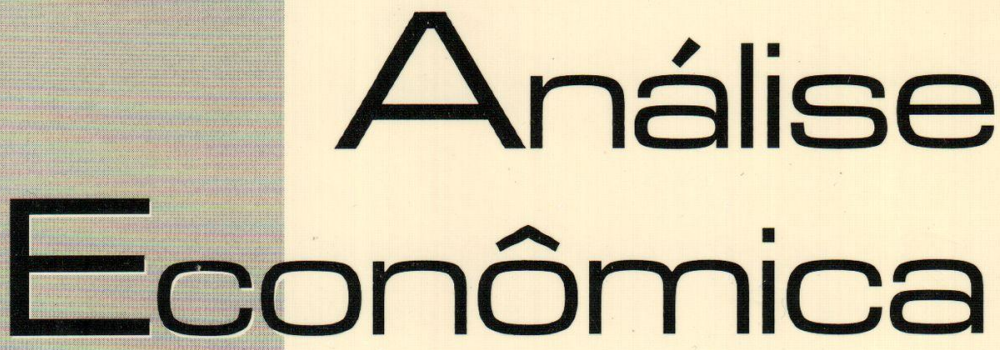

FATOS ESTHLIZADOS E CORRELAÇÁ O NO SETOR BANCÁRIO BRASILEIRO

IGOR AlexandRe C. DE MORAES

Política Monetária, Expectativas e Derivativos: uma ANALISE DO BRASIL PERIODO 1995-98

ROGERIO SOBREIRA

O FEDERAL RESERVE EM DOIS MOMENTOS DISTINTOS: ATUAÇÃO NA GRANDE DEPRESSÃO E NO FINAL DOS ANOS 1990

ROBSON RODRIGUES PEREIRA

BASHLÉIA 2 E ECONOMIAS EMERGENTES: UMA ABORDAGEM MÉDIA-VARIÁNCIA

otaViano Canuto e ANTÓ Nio josé MEIRELLES

VULNERABILIDADES EXTERNAS E INTERNAS DAS ECONOMIAS EMERGENTES E PADRÁ O DE CONTÁ GIO. A EXPERIÉnCIA DA DECADA DE 90

MiLTON PEREIRA OE ASSIS

ENDIVIDAMENTO PÚ BLICO E IMPACTO SOBRE FLUXOS DE CAPITAIS, RISCO-PAIS DIFERENCIAL DE JUROS NO BRASIL (1995-2002): MODELO VAR E TESTES DE CAUSALIDADE FLÁ VIO VILELA VIEIRA

METAS SOCIAIS DE PROCRAMAS DE MICROCRÉ DITO FINANCEIRAMENTE VIÁ VEIS

FERNANDO BATISTA PEREIRA E MARCO CROCCO

Estrutura Produtiva e Performance econó mica das ECONOMIAS ESTAdUAIS BRAsILIRAS NA DECADA DE NOVENTA ADELAR FOCHEZATTO

HISTORIA ECONO MICA Y TEORIA ECONO MICA: ENCUENTROS Y DESENCUENTROS

Gabriel PorciLe

EM BUSCA DA NOÇÃ O EVOLUCIONÁRIA (NEO-

SHUMPETERIANA) DO AUTO-INTERESSE DOS AGENTES: UMA CONTRIBUIÇAO A PARTIR DA LITERATURA SOBRE COOPERAÇÁO INTERFIRMAS

ROBSON ANTONIO GRASS

PRINCiPIOS E APULAÇó Es de REGRESSÁo Local ADALMIR MARQUETTI E LORI VIAL

globalizaçáo, Crescimento e pobreza, a Visäo do BANCO MUNDIAL SOBRE OS EFETTOS DA GLOBALIZAÇÁO NALI DE JESUS DE SOUZA

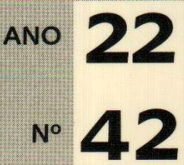




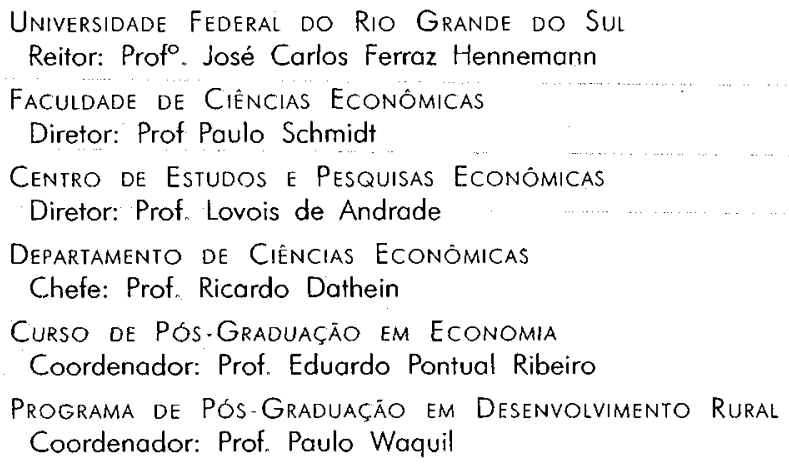

CONSELHO EDITORIAL:

André M. Cunha (UFRGS), Carlos G. A. Mieliz Netto (UFRGS), Carlos H. Hom (UFRGS), Eduardo $A_{n}$ Maldonado Filho (UFRGS), Eduardo P. Ribeiro (UFRGS), Eleutério F. S. Prado (USP), Eugênio Lagemann (UFRGS), Fernando Cardim de Carvalho (UFRJ), Fernando Ferrari Filho (UFRGS), Fernando de Holanda Barbosa (FGV/RJ), Flávio Vasconcellos Comim (UFRGS), Flávio A. Ziegelman (UFRGS), Gentil Corazza (UFRGS), Giácomo Balbinotto Netto (UFRGS), Gilberto de O. Kloeckner(UFRGS), Gustavo Franco (PUC/RJ), Hélio Henkin (UFRGS), Jairo L. Procianoy (UFRGS), Jan A. Kregel (UNCTAD), João Rogério Sanson (UFSC), Joaquim Pinto de Andrade (UnB), Jorge Paulo Araújo (UFRGS), José R. Iglesias (UFRGS), Júlio C. Oliveira (UFRGS), Luis P. Nogueról (UFGS), Luiz E. Faria (UFRGS), Marcelo S. Portugal (UFRGS), Maria Alice Lahorgue (UFRGS), Octávio A. C. Conceição (UFRGS), Orlando Martinelli (UFRGS), Paul Davidson (University of Tennessee), Paulo D. Waquil (UFRGS), Paulo Schmidt (UFRGS), Pedro C. D. Fonseca (UFRGS), Philip Arestis (University of Cambridge), Ricardo Dathein (UFRGS), Roberto C. de Moraes (UFRGS), Ronald Otto Hillbrecht (UFRGS), Sérgio M. M. Monteiro (UFRGS), Sabino da Silvo Porto Jr. (UFRGS), Stefano Florissi (UFRGS) e Werner Baer (University of Illinois at Urbana-Champaign).

COMISSÃO EDITORIAL:

Eduardo Augusto Maldonado Filho, Fernando Ferrari Filho, Gentil Corazza, Marcelo Savino Portugal, Paulo Dabdab Waquil e Roberto Camps Moraes.

EDITOR: Prof. Fernando Ferrari Filho

Egitor Adunto: Prof Gentil Corazza

Secretário: Paulo Roberto Eckent

REVISÁO DE TEXTOS: Vanete Ricacheski

Eottoraçáo Eletrónca: Nucleo de criação e editoraçáo Gráfica UFrgs: leonardo ponso Fundador: Prof. Antônio Carlos Santos Rosa

Os materiais publicados na revista Análise Econômica são da exclusiva responsabilidade dos autores. É permitida a reprodução total ou parcial dos trabalhos, desde que seja citada a fonte. Aceita-se permuta com revistas congêneres. Aceitam-se, também, livros para divulgação, elaboração de resenhas e recensōes Toda correspondência, material para publicação (vide normas na terceira capa), assinaturas e permutas devem ser dirigidos ao seguinte destinatário:

PROF. FERNANDO FERRAR! FILHO

Revista Análise Econômica - Av. João Pessoa, 52 CEP 90040-000 PORTO ALEGRE - RS, BRASIL Telefones: (051) 316-3513 - Fax: (051) 316-3990

Análise Econömíca E-mail: rae@ufrgs.br

Ano 22, $n^{\circ} 42$, morço, 2004 - Porto Alegre

Faculdade de Ciências Econômicas, UFRGS, 2004

Periodicidade semestral, março e setembro.

Tiragem: 500 exemplares

1. Teoria Econômica - Desenvolvimento Regional -

Economia Agrícola - Pesquisa Teórica e Aplicada.

Periódicos. 1. Brasil.

Faculdade de Ciências Econômicas,

Universidade Federal do Rio Grande do Sul. 


\section{Política monetária, expectativas e derivativos: uma análise do Brasil no período 1995-98'}

Rogério Sobreira ${ }^{2}$

Resumo: $\mathrm{O}$ artigo discute os impactos das informações geradas pelos derivativos de taxas de juros sobre a condução da política monetária no Brasil no período 1995-98, sob o regime do câmbio fixo. Parte-se da tese que a taxa de juros de longo prazo é determinada pelo nível da taxa de juros básica de curto prazo (taxa $s p o t$ ), à qual se adicionam as expectativas a respeito do seu comportamento no futuro (taxas a termo esperadas) e um prêmio de risco determinado (a) pelos custos de transação associados às migrações de portfólios; (b) grau de confiança nas expectativas a respeito do comportamento futuro da taxa de juros de curto prazo; (c) data de realização do investimento; (d) grau de disposição a correr risco de capital; e (e) duração do portfólio. $O$ artigo mostra que a inclusão de derivativos tende a volatilizar as expectativas quando o ambiente econômico é percebido como mais instável, levando à imposição de maiores prêmios de risco, intensificando os efeitos das crises de confiança e, com isso, dificultando as ações da autoridade monetária no sentido de determinar a taxa de longo prazo. Especificamente no caso do Brasil, o artigo mostra também que, diferentemente da experiência internacional, a piora das avaliações comunicada através dos derivativos dificultou até mesmo a formação da taxa básica de juros nos períodos que antecederam as crises asiática e russa.

Palavras-chave: derivativos, expectativas, política monetária, taxa de juros.

Abstract: The paper discusses the impacts of the information that arise from the interest rate derivatives on the conduct of the monetary policy in Brazil during 1995-98. The paper shows that the long-term rate of interest is determined by the level of the current short-term rate of interest (spot rate) plus expectations about its behavior on the future (the so-called forward short-rate) plus a risk premium. This premium is determined by the (a) transaction costs of migrate from on portfolio to another; (b) degree of confidence on the expectations of the behavior of the short rate in the future; (c) date of realization of the investment; (d) degree of risk of capital aversion; and (e) duration of the portfolio. The paper shows that when considering derivatives in the economic environment, these expectations tend to be volatilized, and confidence crises become more huge. As a consequence, the risk premium becomes higher, lowering the ability of the central bank to determine the long-term rate. In the

\footnotetext{
${ }^{1}$ Versão ligeiramente modificada dos capitulos 3 e 4 de minha tese de doutorado (Sobreira, 2002), defendida sob a orientação do professor Fernando Cardim de Carvalho, a quem agradeço os valiosos comentários.

${ }^{2}$ Professor-adjunto de Economias e Finanças da EBAPE/FGV. E-mail: sobreira@fgv.br.
} 
case of Brazil during 1995-98, the paper also shows that the worst evaluation of the economic scenario, as shown by the derivatives market, led to a difficult to keep even the spot rate in the level desired by the central bank.

Keywords: derivatives, expectations, rate of interest.

Classificação JEL: E43, E44, E52.

\section{Introdução}

A discussão a respeito da determinação da taxa de juros conduzida nos cânones da teoria pós-keynesiana (KEYNES, 1964) considera que (a) a taxa de juros de longo prazo é um fenômeno estritamente monetário; e (b) não obstante existir algum grau de endogenidade da oferta de moeda, o que se deseja é analisar os impactos das alterações exógenas da oferta de moeda promovidas pelo banco central, no que Davidson (1994, p. 136) denominou de "processo de mudança de portfólio". Em outras palavras; a discussão a respeito da determinação da taxa de juros de longo prazo - ou da sua relação com movimentos na taxa de juros de curto prazo - e os impactos trazidos com a introdução de derivativos de juros é conduzida no âmbito estrito do processo acima aludido, sem considerar seus possíveis efeitos sobre a demanda de ativos reprodutíveis.

No que segue, a seção 2 analisa a determinação do prêmio de risco e a relação entre movimentos na taxa de juros de curto prazo decorrentes das ações da autoridade monetária no mercado monetário (mercado aberto) e seus impactos sobre as taxas de longo prazo, via comportamento deste prêmio, em uma economia sem derivativos. A seção 3 mostra como a introdução dos derivativos de taxa de juros vai influir na determinação deste prêmio, destacando a utilização destes instrumentos para fins de formação das convenções. Mostra-se aqui que a comunicação de expectativas desfavoráveis para o prêmio de risco à vista se dá de forma extremamente rápida, intensificando os efeitos adversos das crises de confiança. A seção mostra também que as sinalizaçōes oriundas deste mercado vão ser utilizadas pelo banco central na configuração de sua política, sem, no entanto, seguir mecânica e automaticamente as indicações apresentadas. A seção 4 discute a relação entre política monetária e derivativos na economia brasileira no período 1995-98, 
mostrando que a instabilidade sinalizada pelos derivativos dificulta até mesmo a formação da taxa de curto prazo no mercado monetário, onde o banco central em tese não experimentaria dificuldades para fazê-lo face à sua condição de monopolista no mercado de reservas. A seção 5 apresenta as conclusões.

\section{Políica monetória e prêmio de risco}

De acordo com a teoria pós-keynesiana (CARVALHO, 1994; DAVIDSON, 1994), a política monetária opera induzindo os agentes econômicos a compras ou vendas de títulos em antecipação a movimentos da taxa de juros. Tais ações ocorreriam sempre que fosse vislumbrada a possibilidade de ganhos de arbitragem entre valores correntes e normais de um título - ou entre os preços relativos e normais dos diversos títulos existentes. Bancos centrais atuariam, assim, modificando o estoque de moeda de modo a alterar a taxa de juros sobre os ativos líquidos e, com isso, engendrar efeitos-substituição nos portfólios individuais.

A magnitude da alteração dos preços relativos dos ativos em relação à estrutura normal decorrente das ações do banco central vai depender das expectativas dos agentes quanto ao movimento futuro dos preços dos títulos e seu impacto sobre a renda total fornecida pelos mesmos. Neste sentido, é importante observar que a taxa de juros de longo prazo será, via de regra, mais elevada que a taxa de juros de curto prazo por conta da inclusão de um prêmio de risco face à incerteza em relação ao comportamento futuro da taxa de curto prazo (HICKS, 1939, p. 147).

O prêmio de risco - ou prêmio de liquidez - vai refletir as alterações observadas nas expectativas individuais e mudanças no estado de confiança (KAHN, 1972; KREGEL, 1998, 2000). A relação entre taxa de curto prazo e taxa de longo prazo, ou, alternativamente, a estrutura a termo da taxa de juros, é assim influenciada decisivamente pelo tratamento dado ao prêmio de risco. Desta forma, assumir, tal como é feito na teoria das expectativas da estrutura a termo (SHILLER, 1990, p. 645), que o prêmio de risco é invariante no tempo, é ignorar a possibilidade de modificações nos cálculos prospectivos dos agentes, bem como os efeitos decorrentes das mudanças no estado de confiança, nas convenções, nos prazos de retenção e da própria acumulação de experiência individual. 
Em uma economia sem mercados derivativos, a política monetária tem sua eficácia condicionada à estabilidade das expectativas que definem a trajetória esperada da taxa de juros $s p o t$ no futuro e do estado de confiança que rege o comportamento do prêmio de risco. Como ensina Keynes (1964, p. 202-3, grifos nossos), "the rate of interest is a highly psychological phenomenon. [...] [T] has fallen to a level which, on the basis of past experience and present expectations of future monetary policy, is considered "unsafe" by the representative opinion."

Assim, na ausência de derivativos, ou na ausência de mercados futuros suficientemente organizados, em que a informação a respeito do preço futuro (médio) esperado dos ativos possa ser obtida livremente e sem custos, ou, mais especificamente, em que o agente possa confrontar sua expectativa com aquela do mercado, o prêmio de risco tenderá a ser menos volátil quando comparado com uma economia onde existem derivativos, tal como ocorre na comparação entre uma economia com um mercado de títulos de dívida altamente organizado e outra na qual este mercado inexiste ou é incipiente. Como observa Keynes (idem, p. 170):

As when we were discussing the marginal efficiency of capital, the question of desirability of having a highly organized market for dealing with debts presents us with a dilemma. For, in the absence of an organized market, liquidity-preference due to the precautionary-motive would be greatly increased; whereas the existence of an organized market gives an opportunity for wide fluctuations in liquidity-preference due to speculative-motive.

Nestas circunstâncias, a volatilização dos prêmios de risco que acompanha a introdução dos derivativos vai contribuir para instabilizar as expectativas a respeito da trajetória futura da taxa de juros e, com isso, vai diminuir a eficácia da política monetária, notadamente quando os derivativos sinalizam uma maior incerteza ou maior divergência de opiniões, como será visto na seção seguinte.

\section{Derivativos, expectativas e polífica monetária}

Um contrato derivativo é usualmente definido como um instrumento financeiro cujo perfil de rendimento (payoff) é determi- 
nado pelo valor do ativo subjacente. A introdução dos mercados derivativos cria, assim, um espaço no qual os agentes podem confrontar suas expectativas a respeito do comportamento esperado para a taxa de juros de curto prazo e, conseqüentemente, para taxa de juros de longo prazo. ${ }^{3}$

Dado o impacto normativo dos modelos de precificação utilizados para valorar tais instrumentos, ${ }^{4}$ as informações oriundas destes mercados exercem uma considerável influência sobre as decisões individuais, não apenas na constituição ou manutenção de suas posições nestes mercados, mas também nos mercados à vista. Some-se a isso o fato de que as operações derivativas caracterizam-se por um elevado grau de alavancagem e, como tal, os equívocos são duramente castigados na forma de perdas significativas. Por todas essas razões, o grau de confiança atrelado às indicações fornecidas pelos derivativos é usualmente elevado.

As informações fornecidas por tais mercados são basicamente de três tipos: (a) indicadores a respeito da média das opiniōes quanto ao comportamento futuro da taxa de juros de curto prazo (taxa spot futura), tal como exposto nas curvas de rendimento esperadas dos futuros de juros; (b) indicadores do grau de volatilidade - ou homogeneidade - destas expectativas expresso na volatilidade implícita dos contratos de opções e variância dos preços futuros; e (c) indicadores a respeito do comportamento do prêmio "médio" de risco (consenso de mercado) tal como evidenciado pelo spread de rendimento dos contratos de swap.

Apesar de as sinalizações fornecidas por tais indicadores não serem precisas (não-tendenciosas) porquanto viesadas pela inclusão de uma série de prêmios de risco (CAMPBELL et al., 1997, p. 379) - o que dificulta uma separação adequada entre variações devidas a mudanças nas expectativas a respeito do nível de atividade, devidas a mudanças nas expectativas inflacionárias ou mudanças no estado de confiança -, as mesmas são úteis para fins de comparação com as expectativas individuais (crosschecking) (ECB, 2000, p. 41).

3 Tais contratos também permitem isolar parcialmente os portfólios de eventos adversos como, por exemplo, o risco da taxa de juros.

4 Como observa Merton (1990, p. 281), referindo-se ao modelo de precificação de Black e Scholes (1973): "Black and Scholes [theory] is particularly attractive because it is a complete equilibrium formulation of the problem [the option pricing] and because the final formula is a function of "observable" variables, making the model subject to empirical tests." Ver também Neftci (1996), p. xviii-xix. 
A introdução desses instrumentos tem, assim, um efeito sobre os mercados de dívidas semelhante àquele observado por Keynes ao se referir às bolsas de valores, qual seja, volatilizar as ações e expectativas individuais dos especuladores. Estes agentes, como também observado por Keynes, não estão preocupados em formular expectativas de longo termo a respeito do rendimento de um investimento (inclusive financeiro) ao longo de sua vida, ou seja, tais indivíduos não se comportam como "viúvas e órfãos" que adquirem títulos com o intuito de auferir o rendimento até a maturidade (yield to maturity), mas sim em "foreseeing changes in the conventional basis of valuation a short time ahead of the general public." (1964, ibid., p. 154).

Neste sentido, as sinalizações oriundas dos derivativos vão ter um forte impacto sobre os mercados à vista, haja vista a influência dos modelos de precificação desses instrumentos e os custos de reversão de posições, notadamente no mercado futuro. Nestas circunstâncias, em analogia ao empreendedor, com a existência de mercados futuros organizados, o especulador poderá atuar como um tomador de preço no mercado tradicional, ou seja, pode tomar o preço do título no mercado futuro e comparar com seu próprio preço esperado a fim de tomar sua decisão (DAVIDSON, 1994, idem, p. 66).

É importante notar que a introdução dos derivativos não leva necessariamente à convergência das melhores apostas individuais. Um ambiente de normalidade enseja distintas leituras da volatilidade aplicada aos modelos de precificação destes instrumentos. Uma vez que o critério de precificação dos derivativos baseado no modelo Black e Scholes exige que os agentes formulem hipóteses (expectativas) a respeito da variância que comanda o processo estocástico do preço do ativo subjacente, algum grau de volatilidade nas opiniões é aceitável, em especial para contratos com vencimentos mais longos.

Nestas circunstâncias, as variâncias dos preços praticados nos mercados futuros e do spread de rendimento dos contratos de swap vão fornecer indicações a respeito do grau de dispersão de opiniões ou consenso do mercado a respeito da valorização dos investimentos no futuro próximo. Um grau de dispersão muito elevado vai sinalizar que a convenção na qual a variância do processo estocástico se baseou não é assumida com convicção 
pelos agentes e, como tal, vai indicar uma probabilidade não desprezivel de uma "genuine change in the news over the near future" (KEYNES, ibid., p. 153). Com isso, o grau de confiança atribuído às expectativas individuais é baixo, e o prêmio de risco se eleva, dificultando modificações na taxa de longo prazo a partir de movimentos na taxa de curto.

Paralelamente à variância dos preços praticados no mercado futuro e de swap, o comportamento do spread de rendimento dos swaps e da variância implícita dos contratos de opções contribui para a configuração da mass psychology of the market. $\mathrm{O}$ spread de rendimento pode ser entendido como uma proxy do prêmio de risco, visto estar livre do problema de distorção característicos dos contratos derivativos com prazos de vencimento variáveis, como é o caso dos contratos futuros. Assim, movimentos ascendentes no spread tendem a contaminar os prêmios de risco das operações à vista do mesmo modo que quedas no spread de rendimento sinalizam uma revisão para baixo na trajetória esperada da taxa spot futura e/ou uma elevação no estado de confiança dos agentes. No que se refere à volatilidade implícita dos contratos de opção, quanto maior seu valor, maior a incerteza associada ao processo estocástico do preço do ativo subjacente e, conseqüentemente, maior tende a ser o prêmio de risco das operações à vista.

Vale também notar que, juntamente a estes indicadores, um outro elemento assume um papel essencial na atribuição de utilidade às informações oriundas dos mercados derivativos, qual seja, o grau de liquidez dos contratos, representado pelo número de negócios realizados a um determinado spread, volatilidade implícita ou preço futuro. Assim, contratos cujo número de negócios seja baixo têm pouca ou nenhuma representatividade para os participantes deste mercado e dos mercados à vista, visto representarem uma visão idiossincrática e não a média das opiniões. $O$ investidor profissional, preocupado como está em antecipar mudanças na psicologia do mercado, vai, assim, atrelar um elevado grau de utilidade apenas às informações oriundas de contratos suficientemente líquidos.

A introdução de derivativos, não só pelo seu conteúdo informacional, mas também pela sua dimensão normativa, tende, assim, a acentuar comportamentos especulativos e, com isso, 
instabilizar a formação dos preços dos ativos, notadamente financeiros, e a induzir comportamentos de manada quando a incerteza é mais elevada. ${ }^{5}$

O impacto de situações como essa nas operações à vista é inequívoco. Sempre que os derivativos sinalizam crises de confiança, os prêmios de risco dos títulos à vista vão sendo imediatamente ajustados, inicialmente para os papéis de prazo mais longo para, em seguida, contaminar toda a estrutura a termo. Neste sentido, a existência de mercados derivativos organizados leva a uma volatilização do prêmio de risco, porquanto comandados pelas leituras dos agentes das informações provenientes destes mercados, intensificando os efeitos das crises de confiança. Nestas circunstâncias, a autoridade monetária percebe uma nítida redução de sua margem de manobra, visto ser incapaz de interferir nos resultados destes mercados. ${ }^{6}$ Assim, o banco central também é premido pela incerteza a respeito das reações do mercado às suas atitudes e sinalizações.

\section{Política monetária e derivativos no Brasil: 1995-98}

$\mathrm{Na}$ seção anterior, discutiu-se como os instrumentos derivativos sinalizam as expectativas dos agentes a respeito do comportamento futuro da taxa de juros, do grau de aderência à convenção e do grau de confiança na política monetária.

Discute-se agora se o Banco Central do Brasil (BCB) se utilizou destas informaçōes e, em caso positivo, de que forma reagiu a elas. Neste sentido, a reação inclui a utilização de todos os instrumentos de política monetária - recolhimento compulsório, redesconto e operações de mercado aberto - e não apenas a modificação propriamente dita da taxa de juros.

A análise a seguir segmenta o período estudado tendo como base o comportamento do mercado futuro e de swap, discutindo

${ }^{5}$ Como observa Banerjee (1992, p. 808): "Herding can make sense when the private return of adopting a particular course of action is an increasing function in the number of agents that adopt the same course of action."

- Garcia e Rezende (1996) mostram que a maior dispersão das propostas submetidas aos leilóes de emissão de títulos da dívida pública está associada ao grau de incerteza da taxa de juros que prevalecerá no futuro. Assim, notam que a maior dispersão observada no mercado futuro de juros no Brasil pós-Plano Real explica não apenas a referida dispersão de propostas de Bônus do Banco Central como também o maior número de propostas não aceitas pela autoridade monetária nos leilôes desses papéis neste período. 
como se deu a condução da política monetária naquelas fases onde os indicadores destes mercados sinalizavam forte confiança na autoridade monetária e naquelas em que esta confiança se deteriora a fim de buscar sinais de modificações na política monetária que, de algum modo, tenham sido provocados por esta deterioração ou que possam ser entendidos como ações visando ao resgate da confiança. ${ }^{\text {t }}$

Uma vez que informações a respeito do grau de dispersão das propostas dos agentes nos leilões de títulos públicos não estão disponiveis, a análise a respeito do grau de dificuldade do BCB em "fazer" a taxa de juros de curto prazo se concentra no total de propostas e no número de propostas aceitas e recusadas dos leilões de títulos públicos.

\subsection{Derivativos e expectativas}

Como já observado, as informações oriundas dos mercados de derivativos de taxa de juros fornecem uma indicação, ainda que imprecisa, do consenso de mercado (ou convenção) a respeito do comportamento esperado para a taxa de juros (nominal e real) e o grau de aderência dos agentes a esta convenção.

A análise do comportamento das expectativas de mudanças na taxa básica de juros no período selecionado é feita tomandose por base a taxa de juros implícita nos contratos futuros da taxa média de depósitos interfinanceiros de um dia - a taxa DI. Nestes contratos, a cotação é dada pelo preço unitário (PU) - definido como $R \$ 100.000,00$ - descontado pela acumulação das taxas médias diárias de DI de um dia calculadas pela Central de Custódia e Liquidação Financeira de Títulos - Cetip.

A taxa de juros assim estimada é utilizada para a construção da curva de rendimento esperada pelo mercado futuro. Em função da maior representatividade decorrente da sua liquidez, foram consideradas apenas as taxas projetadas para um horizonte de até 180 dias úteis. Como não existem taxas observadas para todos os dias contidos neste intervalo, a curva de rendimento esperada foi obtida por interpolação, utilizando-se para tal uma

7 Em face à ausência de consenso a respeito do melhor modelo de precificação de derivativos de taxa de juros (HULL, 2000, p. 601), não utilizamos na análise a seguir a volatilidade implícita dos contratos de opção como um indicador adequado das expectativas. 
função spline cúbiea: $:^{8}$ Esta curva fornece indicações relevantes a respeito das expectativas dos agentes - ou do consenso do mercado - quanto ao comportamento da taxa de juros que irá vigorar para o período compreendido entre a data de negociação e o último dia de negociação ou data de vencimento do contrato.

Estas expectativas, contudo, são viesadas por duas classes de fatores: a data de vencimento variável - e decrescente - dos contratos, que vai fazendo com que a taxa esperada se aproxime cada vez mais da taxa observada, e os custos de transação envolvidos na manutenção das posições futuras, como já aludido. Desta forma, as taxas implícitas nos períodos excessivamente longos e nas datas muito próximas ao vencimento perdem qualidade enquanto sinalizadores das expectativas. ${ }^{9}$

Os dados referentes a estes mercados foram organizados de acordo com o primeiro, o segundo, o terceiro até o enésimo contrato a vencer em cada dia do mês especificado, seguindo o procedimento sugerido por Duffie (1989). Posteriormente, foi extraída uma taxa implícita média de comportamento do mês por dia útil de vencimento. Relacionando-se estas taxas médias com os dias úteis de vencimento, chega-se à curva de rendimento esperada para um determinado mês.

\subsubsection{Mercado futuro}

O ano de 1995 inicia-se com a emergência da crise mexicana, que sofre um ataque especulativo com repercussões sobre as economias emergentes da América Latina. A trajetória de queda da taxa básica de juros que vinha sendo seguida só é efetivamente interrompida no início de março, quando a autoridade eleva a taxa Selic a $4,5 \%$ a.m. Esta mudança na taxa básica ainda não era sinalizada pelo mercado futuro em janeiro. Isto fica evidenciado da observação da curva de rendimento esperada, praticamente

\footnotetext{
${ }^{8}$ A função spline cúbica é, reconhecidamente, a única que preserva as características do comportamento da taxa de juros, sendo desta forma indicada pela literatura para a interpolação das curvas de rendimento. Para detalhes da função e sua utilização, ver Campbell et al., 1997, p. 412. Para críticas a esse procedimento, ver Shea, 1985.

9 "[O] preço futuro corrente reflete a informação corrente que se tem sobre o preço à vista na data de entrega; se a informação chega mais rápido à medida que a data de entrega se aproxima, deve-se esperar uma maior volatilidade dos preços quanto mais perto se estiver da data de vencimento do contrato." (GARCIA, 1994, p. 14).
} 
horizontal nesse período, bem como pela variância das taxas implícitas muito próximas a zero para os vencimentos de 30 e 60 dias úteis.

A deterioração das expectativas já fica evidente no mês de fevereiro. A curva de rendimento esperada já sinalizava uma eleva. ção na taxa de juros, tal como indicado pela sua inclinação negativa e a sinalização de uma taxa curta da ordem de $5 \%$ a.m. Os agentes, antecipando-se à mudança na taxa básica de juros, já projetavam uma curva de rendimento negativamente inclinada para contratos com até 60 dias de vencimento. Nesse ambiente, o nível de incerteza eleva-se sobremaneira, levando a uma maior dificuldade em formar a convenção. Isto fica nítido na comparação entre as variâncias das taxas de juros implícitas nos contratos futuros para os vencimentos de 30 e 60 dias úteis de janeiro e fevereiro, a qual é cerca de 10 vezes superior à do primeiro mês do ano, o que reflete o maior ruído na informação que chega ao mercado.

Nos meses seguintes, notadamente em março e abril, a curva de rendimento esperada mantém-se praticamente horizontal, refletindo as expectativas de manutenção da política de juros elevados. O consenso, contudo, virtualmente inexiste quando se trata das expectativas para um prazo superior a 30 dias úteis, como pode ser notado pelo comportamento da variância das taxas implícitas no mês de março para vencimentos de 60 dias úteis, que atinge valores anormalmente elevados (maiores que 50) para praticamente todo o mês. O mesmo começa a ser restaurado em abril para se recuperar inteiramente no mês de junho, quando as variâncias para esses vencimentos voltam a ficar próximas a zero.

O que se observa nos meses seguintes é uma repetição do quadro observado em junho. Assim, as curvas de rendimento esperadas mantêm-se praticamente horizontais, e as variâncias para os vencimentos de 30 e 60 dias úteis permanecem suficientemente baixas, aos níveis de janeiro e junho daquele ano.

A análise desses indicadores para o ano de 1996 mostra que esta foi uma longa fase de estabilidade, com a autoridade monetária não enfrentando dificuldades para moldar o consenso de mercado. As variâncias das taxas implícitas para os vencimentos de 30,60 e 180 dias úteis permanecem praticamente iguais a zero durante todo o primeiro semestre. As curvas de rendimento esperadas vão gradativamente exibindo o formato padrão (positivamente inclinada), refletindo a crescente confiança na política monetária. 
A partir de agosto, as variâncias para os vencimentos de 180 dias úteis começam a se elevar, em um processo que acaba por contaminar os vencimentos mais curtos ao final do ano.

Este processo pode ser atribuído à mudança observada nas regras do redesconto e à criação da TBC e TBAN que, ao confinar a determinação da taxa básica (Selic) a um corredor, eleva a dispersão de opiniões a respeito do seu valor. Tanto é assim que, durante os meses de agosto e setembro, a Selic efetiva descola ligeiramente da TBC, voltando a operar na vizinhança desta apenas a partir do final desse bimestre. A gradual ampliação do intervalo entre a TBAN e a TBC contribui sobremaneira para dificultar a convenção, com a variância das taxas implícitas para os períodos mais curtos de tempo elevando-se mês a mês. Em outras palavras, a implementação do "corredor" de juros injeta uma dose adicional de ruído nas expectativas a respeito da taxa básica de juros para um horizonte curto de tempo (até 60 dias úteis), fato que colabora para dificultar o consenso para este período e, principalmente, "polui" a informação oriunda do mercado futuro de juros.

O comportamento do mercado futuro ao final de 1996 e primeiros meses de 1997 revela os primeiros sinais de perda de confiança na política ao apresentar curvas de rendimento negativamente inclinadas. As curvas só voltam a exibir o padrão normal em maio daquele ano (1997). A restauração desse padrão normal, contudo, não pode ser lida como um resgate da confiança na política, haja vista a crescente inclinação apresentada pelas curvas de rendimento esperadas. As taxas mais elevadas projetadas por estas curvas sinalizam a elevação do prêmio de risco, indicando uma incerteza crescente em relação ao comportamento da taxa básica. Essa maior incerteza acaba finalmente por contaminar o consenso do mercado quanto à viabilidade da política de redução das taxas básica em outubro, como atestam as variâncias das taxas implícitas nos contratos futuros. ${ }^{10}$

A elevação da TBC, TBAN e Selic ao final de outubro naturalmente altera a inclinação da curva de rendimento esperada sem, no entanto, resgatar o consenso a respeito de seu comportamento futuro. A dispersão de opiniões segue durante todo o ano

10 Ao final daquele mês, as variẩncias para os vencimentos de 30,60 e 180 dias úteis exibiam valores em torno de 0,02 contra valores virtualmente identicos a zero para os meses anteriores do ano. 
de 1998, com as curvas de rendimento mantendo a inclinação negativa até abril e passando a exibir inclinações positivas e crescentes nos meses de maio a agosto. Em setembro, com a alta observada nas taxas básicas, as curvas voltam a apresentar inclinação negativa até o final do ano. As variâncias das taxas implícitas, por seu turno, seguem apresentando valores cada vez mais elevados mês a mês para todos os três vencimentos analisados.

\subsubsection{Swaps}

A análise da evolução das expectativas executada na subseção anterior deve ser complementada com a avaliação do comportamento do spread de rendimento dos contratos de swap de taxa de juros. Como observado, as informações provenientes do mercado futuro apresentam uma série de distorções e podem comprometer a leitura a respeito do grau de confiança atribuído à política monetária, em especial quando se considera horizontes mais longos de tempo.

O spread de rendimento das operações de swap, por sua vez, permite avaliar a existência de um consenso de mercado para prazos mais longos que o curtíssimo prazo utilizado para inferir as expectativas no mercado futuro e, com isso, o grau de confiança depositado na política monetária. Além disso, por prescindir do ajuste diário e chamadas de margem, estes contratos refletem mais puramente as expectativas. Neste sentido, o spread de rendimento pode ser considerado como uma proxy do prêmio de risco exigido pelos agentes e, portanto, como sinalizador do estado de confiança da comunidade.

Em ambientes estáveis, e considerando-se as peculiaridades dos contratos de swap, os agentes sentem-se mais confortáveis para formular expectativas a respeito da evolução da taxa de juros visto que mudanças súbitas e intensas nesta variável serem pouco prováveis. Ambientes voláteis, por outro lado, dificultariam sobremaneira a formação destas expectativas e, portanto, do consenso a respeito da evolução da taxa de juros em horizontes mais distantes.

A partir da avaliação do spread de rendimento é possível também inferir o comportamento do prêmio de risco e da estrutura a termo que estaria embutido no critério de precificação dos swaps, ou seja, qual hipótese da estrutura a termo estaria sendo 
utilizada pelos agentes, e se o comportamento do prêmio de risco mimetiza a reação esperada na curva de rendimento em ambientes mais voláteis e ambientes mais estáveis.

Neste sentido, é importante notar que até meados de 1995 simplesmente não existiam cotações para contratos de swap de DI contra taxas prefixadas para períodos superiores a 30 dias. A partir de então, o prazo das cotações se eleva, mas nunca ultrapassando os 360 dias, além de se observar diversas descontinuidades na informação. O prazo se alonga efetivamente a partir da edição da Circular $n^{\circ} 2.771$, de 31 de julho de 1997, quando o Banco Central do Brasil passa a requerer a divulgação das taxas referenciais de swap para um prazo de, no mínimo, 720 dias, muito embora tais informações sejam de pouca valia em face da inexpressiva liquidez dos contratos mais longos.

Assim, o cálculo do spread de juros - e o conseqüente teste da hipótese de expectativas da estrutura a termo - deveria considerar apenas o período compreendido entre agosto de 1997 e dezembro de 1998, não obstante o mesmo ser curto o suficiente para produzir resultados cujo significado requeira posterior confirmação estatística. De modo a reduzir este problema, tomamos como período inicial o mês de setembro de 1996, visto ser o primeiro mês para o qual se observam cotações mais regulares de swaps de juros para 360 dias de vencimento, últimos contratos para os quais o volume de negócios é representativo. Uma vez que as cotações são descontínuas, utilizamos uma função spline cúbica para aproximar as cotações para aqueles dias em que não existiram negócios, seguindo o mesmo procedimento utilizado para se construir as curvas de rendimento esperada dos contratos futuros.

A hipótese de expectativas da estrutura a termo afirma que as diferenças entre os retornos esperados dos títulos de diferentes prazos de vencimento e mesma qualidade são constantes ao longo do tempo e variam com o prazo de vencimento do título. Estas diferenças são denominadas de prêmio de risco. Segundo esta hipótese, o prêmio de risco é positivo e constante, podendo variar com o prazo de vencimento do papel, mas nunca com o tempo. Apesar da rejeição da hipótese de expectativas para o caso do Brasil no período estudado, ainda é possível analisar o comportamento do spread de rendimento, a fim de se inferir o conteúdo expectacional da estrutura a termo gerada a partir dos dados 
em questão. ${ }^{11}$ Estes ativos ainda embutem um importante conteúdo expectacional posto serem forward-looking por sua própria natureza. Especificamente, em relação aos vencimentos de 30 dias, as mudanças médias na taxa básica sinalizadas pelos spreads de rendimentos são sensivelmente mais elevadas que aquelas observadas pela distribuição das mudanças na taxa DI. Note-se, contudo, que a sinalização das mudanças é, em média, correta.

No período compreendido entre os meses de setembro de 1996 e dezembro do mesmo ano, os spreads de rendimento das operações de $s w a p$ de juros foram hegemonicamente negativos para todos os vencimentos, fato que atesta a confiança na política monetária e econômica, corroborando a confiança exibida pelas curvas de rendimento esperadas dos contratos futuros.

Um spread de rendimento negativo sinaliza expectativas de redução da taxa básica de juros, a taxa variável do contrato de swap. Caso contrário, a equalização esperada dos fluxos de pagamento suposta no contrato de swap não seria passível de ser observada.

No primeiro semestre de 1997, os spreads de rendimento seguem na sua maioria apresentando sinal negativo, indicando mais uma vez uma expectativa de queda da taxa de juros. Contudo, diferentemente do ocorrido em 1996, o comportamento desse indicador para os vencimentos mais longos já se apresenta mais errático, que se intensifica especialmente no segundo trimestre.

Ao final desse segundo trimestre, nota-se também uma outra mudança de comportamento, qual seja, a elevação dos spreads, que se tornam positivos especialmente para os três últimos vencimentos considerados (90, 180 e 360 dias úteis). Esse padrão é confirmado no terceiro trimestre até o advento da crise asiática. Neste sentido, é importante notar a simetria de sinalização entre os spreads de rendimento e as curvas de rendimento esperadas do mercado futuro, que, como visto, também indicava uma expectativa de elevação da taxa básica já a partir do segundo trimestre daquele ano.

Após a crise asiática, nota-se uma intensificação da volatilidade nos spreads de rendimento para todos os vencimentos, revelando mais uma vez a cada vez menor confiança deposi-

11 Para maiores detalhes sobre os testes que rejeitam a hipótese de expectativas a partir das informaçōes oriundas dos contratos de swap, ver Sobreira (2002). Ver também Tabak e Andrade (2001) 
tada na política monetária e econômica. Como esperado, os spreads seguem apresentando valores negativos no primeiro trimestre de 1998. Os vencimentos mais longos (180 e 360 dias úteis), contudo, apontam uma expectativa de elevação da taxa de juros já a partir de fins de abril, em um movimento que se intensifica e vai contaminando os demais vencimentos. Em fins de agosto daquele ano, as expectativas são de forte elevação nas taxas de juros, antecipando a alta que seria observada em outubro.

Os efeitos das crises sobre o grau de confiança dos agentes ficam evidentes quando se analisa a volatilidade - medida pela variância - dos prêmios de risco. Os prêmios de risco para vencimentos mais curtos (30 e 60 dias úteis) tendem, em condições normais - a apresentar uma maior volatilidade em face ao fato da informação sobre a taxa de juros "chegar mais rápido" (GARCIA, 1994, idem). Para prazos de vencimentos mais distantes, também em condiçōes normais, há uma maior convergência de opiniões. É precisamente o que ocorre no segundo semestre de 1996. A variância dos spreads de rendimento para os vencimentos de 90 , 180 e 360 dias são cerca de $50 \%$ inferiores àquelas observadas para os períodos mais curtos.

No primeiro semestre de 1997, a gradual perda de confiança na política monetária se faz presente não só pela elevação no spread, mas também pelo aumento das variâncias do spread para todos os vencimentos, notadamente para os vencimentos mais longos. Mais especificamente, no período compreendido entre os meses de janeiro a outubro de 1997, ou seja, antes da eclosão da crise asiática, as variâncias dos spreads de rendimento para os contratos mais longos já exibiam valores cerca de quatro vezes superiores àqueles observados no segundo semestre de 1996. A perda de confiança evidenciada nas variâncias mais elevadas não foi mais resgatada no ano seguinte, quando, no período janeiro a setembro (até o dia 8), as variâncias dos spreads exibiram valores mais elevados se comparados àqueles dos dez primeiros meses de 1997, com destaque para a magnitude das variâncias dos contratos de 180 e 360 dias úteis.

Os demais contratos também sinalizam corretamente a direção das mudanças na taxa básica. Contudo, uma vez que o prêmio de risco eleva-se à medida que o prazo de vencimento do contrato aumenta, a intensidade da mudança sinalizada declina com o prazo de vencimento. A razão está no fato de que o prêmio de risco 
aparentemente fornece uma remuneração adequada, não havendo assim a necessidade de praticar taxas significativamente elevadas a fim de se proteger contra possíveis perdas de capital em ambientes de intensa volatilidade da taxa de juros, como de resto parece ser a prática corrente nos contratos mais curtos (30 e 60 dias de vencimento). Note-se, inclusive, que esta é a racionalidade esperada em relação ao comportamento das taxas de prazo mais longo. Por fim, é importante observar que a volatilidade das taxas praticadas nestes contratos é significativamente mais elevada que aquela observada em relação ao comportamento da taxa básica.

No período intracrises cambiais (outubro de 1997 a dezembro de 1998) os contratos mais uma vez sinalizaram corretamente a direção dos movimentos da taxa de juros e, mais uma vez, acentuaram sua intensidade. No entanto, nota-se que a diferença de intensidade da mudança diminui relativamente à mudança média observada na taxa DI, o que parece indicar um maior grau de acerto destes instrumentos na antecipação dos movimentos da taxa básica.

\subsection{Política monetária e derivativos}

A formação da taxa de juros básica (Selic) no Brasil no início do período analisado era realizada a partir de leilóes formais de Bônus do Banco Central (BBC), os quais ocorriam tipicamente em uma base semanal. Através dos mesmos, o banco central procurava estabelecer um consenso de mercado para a taxa de juros básica, a qual passou a funcionar como centro de gravidade para as operações de troca de reservas lastreadas em títulos públicos federais. A autoridade também se valeu dos leilões informais a fim de calibrar a taxa básica, de modo a mantê-la na vizinhança do consenso por ela estabelecido.

Em geral, quanto mais difícil a formação do consenso, maior o número de leilóes requeridos para formar a taxa de juros desejada pela autoridade e maior o número de leilões que têm suas propostas inteiramente recusadas. Considerando-se que os BBC são títulos prefixados que não pagam cupom de juros e possuem um prazo de vencimento bastante curto - em média de 3 meses - e, como tal, possuem uma baixa duração e uma baixa exposição ao risco da taxa de juros, a ausência de consenso poderia signi- 
ficar uma expectativa de elevação substantiva da taxa básica a ponto de tornar a rentabilidade destes papéis nula ou negativa. Mais realisticamente, contudo, a ausência ou dificuldade de consenso indicava a incerteza quanto à obtenção daquela taxa de juros desejada pelo detentor do papel.

Desta forma, nas fases de estabilidade, quando uma convenção é mais facilmente construída, o número de leilōes necessários para formar a taxa de juros básica da economia tende a ser substantivamente menor que aquele necessário em ambientes de maior incerteza. Esta relação é facilmente observada no período analisado. Ao longo de 1995, como observado, a taxa selic efetiva tem sua trajetória de declínio interrompida em março, quando sai de uma média mensal de $3,2 \%$ para $4,5 \%$ a.m. . A trajetória de declínio é timidamente retomada em abril, mas a Selic só volta a atingir o valor observado em março ao final de outubro daquele ano.

Tanto na fase de elevação da taxa básica, quanto no período imediatamente anterior, o número de leilões formais de $\mathrm{BBC}$ se eleva, saindo de um total de 16 realizados em janeiro para $18 \mathrm{em}$ fevereiro e 20 em março, elevando-se novamente para $19 \mathrm{em}$ maio ante uma queda para $16 \mathrm{em}$ abril. Apenas a título de comparação, o número médio de leilōes realizados nos quatro últimos meses de 1994 foi da ordem de 13. Após a fase de turbulência, a autoridade passa a necessitar de algo em torno de 12 leilōes para "fazer" uma taxa básica sistematicamente mais reduzida.

Esse maior número de leilões realizados na fase de turbulência deveu-se à dificuldade encontrada pela autoridade em estabelecer o referido consenso de mercado. Assim, o número de leilóes cujas propostas foram inteiramente recusadas pelo banco central é bastante significativo, caindo a valores históricos na segunda metade do ano.

Desta forma, na fase de turbulência que caracterizou o primeiro semestre de 1995, evidenciado nas elevadas variâncias das taxas implícitas nos contratos futuros, a dispersão que parece ter existido nas taxas propostas nos leilões de títulos públicos (BBC) obriga o banco central a recusar um percentual maior de propostas e, com isso, a realizar um número maior de leilóes para formar a taxa de juros desejada.

É importante notar, também, uma mudança ocorrida em outubro de 1995, quando o banco central inaugura um procedi- 
mento de atuação no mercado aberto caracterizado pela constituição de uma banda informal de juros, em uma prévia do que ocorreria em meados de 1996 com a criação da TBC e da TBAN. Diferentemente daquela época, a mudança implementada em 1995 se distingue pela ausência da informação a respeito do intervalo da banda. A autoridade constrói a banda cotidianamente, realizando (ou não) leilóes de recursos.

Essa forma de atuação, por si só indutora de volatilidade da taxa de juros, evita que uma eventual maior dispersão das taxas praticadas no mercado aberto pudesse ser atribuída a "desconfianças" em relação aos rumos e eficácia da política. Em outras palavras, a mudança parece ter como principal propósito a criação de ruído na obtenção de informações e constituição de expectativas a respeito da evolução da taxa de juros básica, com a finalidade de dissipar leituras desfavoráveis à política econômica em geral e à política monetária em particular.

Isto posto, ao longo do primeiro semestre de 1996, o banco central dá seguimento à sua política de redução gradual das taxas de juros, calibrando a intensidade das quedas em função do comportamento das contas externas, taxa de inflação e nível de atividade. Neste sentido, o comportamento observado no mercado futuro indica que a autoridade não enfrentaria maiores dificuldades na condução da política.

Uma vez estabelecida a confiança nos rumos da política monetária e econômica, a necessidade de intervenção por parte da autoridade para confecção da taxa básica de juros se reduz consideravelmente. Assim, em 1996, o número de leilões formais de $B B C$ declina substantivamente no primeiro semestre quando comparado à fase de crise do início do ano anterior.

Como observado, a partir do segundo semestre daquele ano, o mercado futuro começa a sinalizar uma gradual e ainda tímida perda de confiança nesta política expressa no aumento da inclinação da curva de rendimento esperada. A inclinação positiva é inicialmente observada na "cauda" mais longa da curva e vai contaminando os prazos mais curtos sistematicamente à medida que avança o segundo semestre.

Este comportamento não é suficiente para induzir mudanças na política monetária. Ao contrário, em uma clara demonstração de confiança na sua política, o banco central anuncia a criação da TBC e novas regras para o redesconto, tornando assim explí- 
cita a taxa que deveria servir de balizador (ou piso) das operações de troca de reservas entre as instituições. O estabelecimento da banda formal de juros, que passa a operar na sua plenitude a partir de setembro, somada à modificação na sistemática de redesconto, que retira do mesmo o caráter punitivo que caracterizava a utilização deste instrumento, reduz ainda mais a necessidade da realização dos leilões formais para o estabelecimento da taxa básica de juros. Com o novo mecanismo, o banco central objetivava transferir ao redesconto a tarefa de calibrar - e até mesmo de fazer - a taxa básica, o que se reflete na virtual ausência de leilóes informais a partir do segundo semestre do ano.

Em agosto, contudo, o banco central ensaia uma espécie de reação à piora nas expectativas iniciada em junho e confirmada pela elevação nas variâncias das taxas implícitas para vencimentos de 180 dias. Assim, contrariando as expectativas do mercado, ${ }^{12}$ não apenas manteve inalterada a TBC como também atuou ofertando recursos às instituições financeiras com o claro intuito de reduzir a volatilidade das taxas praticadas no mercado aberto.

A partir de setembro, contudo, o banco central retoma sua política de cortes graduais nas taxas, não obstante a maior volatilidade nas taxas básicas, tanto à vista quanto futuras para os vencimentos de 180 dias úteis. Neste sentido, a atuação da autoridade sugere uma tentativa de reverter qualquer tipo de desconfiança através da manutenção da sua política.

Neste sentido, é emblemático o fato de que, mesmo sob notícias desfavoráveis no front fiscal e externo - déficit primário da União e piora nos resultados da balança comercial, o BCB tenha se mantido firme na sua intenção de reduzir as taxas de juros, quando no passado recente tais fatores comprovadamente desempenharam o papel de freios ao gradualismo monetário. Assim, pode-se afirmar que existem nestas reduções uma intenção da autoridade de moldar as expectativas e resgatar o consenso favorável à política monetária em particular e econômica em geral.

\footnotetext{
${ }^{12}{ }^{\mathrm{A}} \mathrm{Ao}$ repetir em agosto a TBC definida para julho, o banco central, além de supreender o mercado, sinalizou de maneira inequívoca que, embora o compromisso de médio prazo continue sendo o de reduzir o custo do dinheiro, o processo de fixação das taxas básicas de juros da economia a partir da observação de fundamentos macroeconômicos, pode implicar, eventualmente, uma inflexão na tendência da curva de juros [...]." (ANDIMA, 1996, agosto, p.1, grifos nossos).
} 
Nota-se, contudo, uma outra mudança sutil na condução da política monetária: o corte promovido na TBC de outubro para novembro $(0,04$ ponto percentual) é inferior àquele executado de setembro para outubro (0,06 ponto percentual) e a TBAN no período compreendido entre os meses de novembro, e dezembro não sofre qualquer alteração, contrariamente ao que ocorreu entre o primeiro e o segundo mês de existência desta taxa. Com isso, o corredor de juros tem seus limites expandidos - a diferença entre a TBAN e a TBC se expande de 0,11 ponto percentual em outubro para nada menos que 0,16 ponto percentual em dezembro - no que parece ser uma tentativa semelhante de confinar a maior volatilidade observada das taxas à vista a um maior intervalo de modo a dificultar a separação entre a maior volatilidade causada por fenômenos passageiros e aquela decorrente de uma piora no estado de confiança na política econômica.

Ainda que o apelo ao redesconto tenha sido menor que o esperado pelo banco central (ANDIMA, 1996, outubro) a mudança na regra por si só reflete a melhoria no estado de confiança dos agentes tal como indicado pelo comportamento das curvas de rendimento esperadas, variâncias implícitas e spread de rendimento.

No primeiro semestre de 1997 percebe-se, no entanto, uma mudança significativa de padrão de comportamento no que se refere ao número de leilões formais de BBC. Contrariando o que havia se observado nos dois anos anteriores, a autoridade realiza um número significativamente maior de leilóes formais, no que aparentaria ser uma maior dificuldade de estabelecimento do consenso. Nota-se que esse maior número de leilóes não decorre de um percentual significativo de propostas recusadas e sim de uma maior quantidade de papéis ofertados com diferentes prazos de vencimento na mesma data de realização dos leilões dos papéis mais tipicamente utilizados. Em outras palavras, a autoridade, nesse primeiro semestre de 1997, aumenta o leque de BBCs ofertados nos leilões formais, em uma clara tentativa de alongar o prazo médio desses papéis. O número de leilões com propostas recusadas nesse primeiro semestre permanece basicamente o mesmo daquele observado em 1996. Não é por outra razão que, a partir do segundo semestre, tais papéis passam a ser ofertados apenas para um prazo mínimo de vencimento de 100 dias úteis. 
As observações provenientes dos mercados derivativos mostram que a ação da autoridade monetária não foi plenamente eficaz. Ao final do primeiro semestre do ano, as curvas de rendimento dos contratos futuros já projetavam uma expectativa de elevação da taxa de juros básica, embora as variâncias das taxas implícitas desses contratos permanecessem suficientemente baixas. No entanto, as variâncias dos spreads de rendimento dos contratos de swap já exibiam valores substantivamente mais elevados se comparados ao segundo semestre de 1996, notadamente para os contratos mais longos. A expectativa de elevação das taxas básicas só fica nítida ao final deste primeiro semestre de 1997, com as curvas de rendimento elevando sua inclinação mês a mês, as variâncias das taxas implím citas para os contratos de 180 dias aumentando sistematicamente, e os spreads de rendimento dos swaps - e suas variâncias - elevando-se também consistentemente.

A reação da autoridade ante a crescente instabilidade nas expectativas é a interrupção da trajetória de queda nas taxas de juros, à qual se soma uma atuação mais agressiva nos leilões formais, tanto com o propósito de elevar o prazo médio dos títulos do banco central detidos pelos agentes quanto para "forçar" uma redução da taxa no curto prazo. No entanto, por ocasião da emergência da crise asiática (agosto de 1997), o número de leilões que têm suas propostas aceitas cai de uma média mensal de 7 para nada menos que 4 , chegando a zero em novembro e dezembro.

$\mathrm{O}$ agravamento do ambiente interno e externo, somado à dificuldade cada vez maior de manter a taxa de juros nos níveis que vinham sendo observados, acaba por levar à alta nas taxas referenciais em outubro.

A elevação da taxa básica, no entanto, é incapaz de resgatar o consenso ou a confiança dos agentes que caracterizou os períodos prévios de estabilidade, notadamente em 1996, como atesta o comportamento dos mercados futuros e de swap. Assim, a dispersão crescente de opiniões segue sendo observada durante todo o ano de 1998. O padrão de comportamento do BCB no que diz respeito ao total de leilōes e ao número de leilóes com propostas recusadas e aceitas é, contudo, essencialmente o mesmo daquele de 1997.

Assim, após a elevação da taxa básica, o BCB procura retomar o mais cedo possível sua política de redução das taxas 
referenciais por entender que a mesma é indutora de confiança dos agentes. Assim, já em dezembro, a TBC e a TBAN são reduzidas, juntamente com a ampliação significativa dos limites do corredor de juros, que passa para 0,25 ponto percentual.

Apesar desta redução nas taxas, o ano de 1998 se inicia sob os efeitos da referida crise, com a curva de rendimento esperada ainda apresentando inclinação positiva no mês de janeiro. Essa inclinação é revertida a partir de fevereiro, mas, longe de representar um resgate da confiança na política monetária, sinaliza a crença de que a elevada taxa ainda praticada naquele início de ano não é sustentável.

O mercado futuro sinaliza o efeito da crise de 1997 no estado de confiança, que contamina o início do novo ano, mostrando uma crescente dispersão das opiniōes dos agentes a respeito da trajetória futura da taxa de juros, representada pela maior volatilidade das taxas implícitas para todos os vencimentos considerados. Os spreads de rendimento dos swaps também apresentam forte tendência de alta já a partir de maio para todos os vencimentos. A autoridade agora é obrigada a operar em um ambiente muito mais desfavorável que aquele anterior à crise de 1997, um ambiente onde a promoção do consenso exige uma atuação mais intensa do Banco Central no mercado monetário.

Esta atuação se faz presente nos leilões informais, em que o Banco Central, contrariando o modelo instituído em 1996, exerce uma forte ação interventora com o firme propósito de mitigar a volatilidade das taxas.

Não obstante, o Banco Central segue reduzindo as taxas referenciais e, novamente, amplia o intervalo do corredor de juros. Contudo, já a partir de maio, a curva de rendimento volta a se inflexionar positivamente, o que, juntamente com as maiores variâncias das taxas implícitas, reflete a gradual destruição da confiança na política. Este fato parece ter provocado o encurtamento do corredor de juros promovido no final daquele mês, ainda que no âmbito da redução das taxas referenciais. Adicionalmente, o banco procura driblar a volatilidade crescente atuando pesadamente no mercado de reservas na condição de tomador. Por conta da incerteza crescente, a autoridade é obrigada, já no início daquele ano, a rever o prazo típico dos Bônus ofertados nos leilōes formais, cujo patamar mínimo declina de 100 para 23 dias úteis. 
Ao final do primeiro semestre, o banco central abandona os leilões de BBC enquanto instrumentos definidores da taxa básica de juros, passando a utilizar Letras do Banco Central (LBC) e Notas do Banco Central, série especial (NBC-E) para este fim. A LBC é um título pós-fixado, cujo valor nominal é corrigido pela taxa Selic. A NBC-E, por seu turno, é também um título pósfixado, que paga taxa de juros fixa de $6 \%$ a.a. cujo valor nominal é corrigido pela variação do dólar comercial. Em face às características destes papéis, e considerando-se o ambiente de crescente instabilidade e incerteza quanto à manutenção da política cambial, a autoridade viu-se obrigada a substituir os BBCs por conta do prazo cada vez mais curto e da taxa de juros (prefixada) cada vez mais elevada exigida pelos agentes para adquirir estes papéis. ${ }^{13}$

A partir de outubro de 1998, as LBCs são substituídas por um novo título, os Bônus do Banco Central, série $\mathrm{A}$ (BBC-A). Estes são papéis híbridos, cuja rentabilidade era composta em parte pelo desconto do seu valor de resgate conhecido e em parte pela correção do seu valor de face pela taxa Selic. Esta foi a solução encontrada pela autoridade para evitar o ágio crescente que vinha sendo observado nos leilōes das Letras do Banco Central, ${ }^{14} \circ$ qual advinha da maior demanda por hedge - tanto contra o risco da taxa de juros quanto contra o risco cambial - dos agentes.

A utilização dos novos papéis resgata, ainda que temporariamente e às custas de transferir para o banco central o risco da taxa de juros, a capacidade de formação da taxa de juros básica dos leilōes formais. A taxa projetada nos leilões só volta a sinalizar um patamar superior de taxa de juros no curto prazo em dezembro, na vizinhança da crise que levou à mudança do regime cambial.

${ }_{13}$ A taxa projetada nos leilōes de $\mathrm{BBC}$ vinha, no início do ano, localizando-se bastante próxima - e algumas vezes abaixo - da taxa Selic efetiva. A partir do final de abril, a taxa projetada nos leilóes inicia um processo de descolamento, chegando a ficar quase dois pontos percentuais acima da selic efetiva.

${ }_{14} \mathrm{O}$ maior ágio reflete a maior incerteza entre os agentes a respeito dos riscos aludidos acima, o que, como já observado, dificultava sobremaneira a formação do consenso a respeito da taxa de juros básica. Essa maior incerteza também é refletida no número de leilōes que têm suas propostas recusadas enquanto proporção do total Em junho, quando os leilóes de LBC tiveram início, a recusa representava cerca de $50 \%$ do total dos leilöes. Em agosto este percentual se eleva para $56 \%$ e para nada menos que $83 \%$ em setembro, quando estes papéis deixam de ser utilizados. 
Neste contexto de piora das expectativas, o banco central também se utiliza fortemente dos leilões informais a fim de "fazer" a taxa de juros, contrariando inclusive a filosofia do mecanismo da assistência de liquidez implementado pela própria autoridade em meados de 1996. Assim, já a partir de março são realizados nada menos que 15 leilões informais com o banco central na condição de tomador. Este número é substantivamente reduzido em abril e maio, voltando a crescer em junho para não mais declinar até o final do ano.

No entanto, em face das expectativas mais desfavoráveis, o Banco encontra maiores dificuldades para formar um consenso, que se esgarça velozmente. Agora, a comunicação das expectativas desfavoráveis observada nos mercados derivativos para as operações à vista ocorre com muito mais rapidez e intensidade. Mesmo assim, a taxa de juros básica é sistematicamente reduzida até setembro, com a assistência de liquidez desempenhando seu papel de disciplinador da taxa praticada nas operações interbancárias.

Percebe-se assim, ao longo do período analisado, que as mudanças na taxa de juros são uma espécie de último expediente ao qual a autoridade recorre quando todas as demais formas de contenção da volatilidade das taxas básicas parecem esgotadas, notadamente nas fases que antecedem as crises. Através de um maior número de leilões formais, de uma atuação mais intensa na condição de tomador ou doador de recursos, modificações nos papéis utilizados nos leilóes e outros expedientes semelhantes, o Banco Central do Brasil tenta forçar um consenso de mercado na esperança de mitigar a maior incerteza que antecede as crises de balanço de pagamento enfrentadas pelo país.

\section{Conclusão}

A análise acima mostrou que os derivativos fornecem importantes - ainda que viesadas - informações a respeito das expectativas e grau de confiança dos agentes nos rumos da política monetária, em particular e política econômica em geral. Mostrou-se também que o comportamento do prêmio de risco do mercado à vista, no qual é formada a taxa de juros tanto de curto quanto de longo prazo, é extremamente sensível às sinalizações oriundas dos 
mercados derivativos. Como tal, um consenso desfavorável nos mercados futuros, de opções ou swap, tem o poder de instabilizar sobremaneira o prêmio de risco à vista e, assim, dificultar a formação da taxa de juros desejada pela autoridade.

Por estas razões, tais informações devem fazer parte de qualquer função de reação de um banco central típico, sem que isso signifique, contudo, que o banco seja obrigado a confirmar as sinalizações fornecidas por tais indicadores, visto que as mesmas são poluídas pela inclusão de diversos prêmios de risco. $O$ que parece ser a forma correta de utilização destas informações pela autoridade monetária é como instrumento de checagem da consistência da sua política.

No caso específico do Brasil no período analisado, o BCB parece ter se tornado gradativamente mais sensível às indicações de tais mercados. Neste sentido, observou-se que seu padrão de atuação visou claramente à formação do consenso favorável à sua política, mesmo quando as sinalizações dos mercados futuro e de swap sugeriam um nítido esgotamento da mesma, com o agravante de que a autoridade experimentou crescentes dificuldades não para influir na formação da (inexistente) taxa de longo prazo e sim para a formação da taxa de curto prazo, onde seu poder monopolista no mercado de reservas bancárias em tese seria capaz de lhe conferir poderes absolutos na formação da taxa.

\section{Referências bibliográficas}

ANDIMA. (1996). Sinopse mensal. Vários números. Rio de Janeiro: Associação Nacional das Instituiçōes do Mercado Aberto. As referências são indicadas por Andima, seguido de 1996 e do mês.

BANERJEE, A.(1992). A simple model of herd behavior. Quarterly Joumal of Economics, 107(3), p. 797-817.

BLACK, F. e M. SCHOLES.(1973). The price of options and corporate liabilites , Journal of Political Economy, 81, 399-418.

CAMPBELL, J., A. LO e A. MACKINLAY. (1997). The econometrics of financial markets. Princeton, New Jersey: Princeton University Press.

CARVALHO, F.(1994). Temas de política monetária keynesiana. Ensaios FEE15(1), janeiro, p. 33-61.

DAVIDSON, P. (1994). Post Keynesian macroeconomic theory. Aldershot: Edward Elgar. DUFFIE, D.(1989). Futures Market. New Jersey: Prentice-Hall. 
ECB.(2000). The information content of interest rate and their derivatives for monetary policy. Frankfurt: European Central Bank, Monthly bulletin, p. 37-57, março.

GARCIA, M.(1994). O mercado futuro da taxa de juros no Brasil: especificidades teóricas e empíricas do mercado de DI futuro. Rio de Janeiro: PUC-RJ. Texto para discussão n. 318.

GARCIA, M. e REZENDE, L.(1996). Leilóes de títulos da dívida pública pelo Banco Central do Brasil: um estudo dos fatores condicionantes da dispersão das propostas para os $B B C S$. Rio de Janeiro: PUC-RJ. Texto para discussão n. 360.

HICKS, J.R.(1939). Value and capital. Oxford: Oxford University Press.

HULL, J.(2000). Options, futures and other derivatives. New Jersey: Prentice Hall. $4^{a}$ edição.

KAHN, R.(1972). Some notes on liquidity preference in Selected essays on employment and growth. Cambridge: Cambridge University Press.

KEYNES, J.M.(1964). The general theory of employment, interest and money. New York: Harcourt Brace.

KREGEL, J.(1998). Aspects of a post Keynesian theory of finance. Joumal of Post Keynesian Economics, 21(1), outono, p.111-133.

KREGEL, J.(2000). Krugman on the liquidity trap: why inflation won't bring recovery in Japan. Economia, 1(1), janeiro, pp.39-58.

MERTON, R.(1990). Continous-time finance. Oxford: Basil Blackwell.

NEFTCI, S.(1996). An introduction to the mathematics of financial derivatives San Diego: Academic Press.

SHEA, G.(1985). Interest rate term structure estimation with exponential splines: a note. The Journal of Finance, 40(1), março, pp. 319-325.

SHILLER, R.(1990). The term structure of interest rate. in Friedman, B. e F. Hahn (eds.). Handbook of monetary economics. Amsterdam: North Holland. Vol. 1.

SOBREIRA, R.(2002). Derivativos, informação de mercado e política monetária. Rio de Janeiro: Instituto de Economia. Tese de doutorado. mimeo.

TABAK, B. e S. ANDRADE. (2001). Testing the expectations hypothesis in the Brazilian term structure of interest rates. Brasilia, DF: Working paper n. 30. 